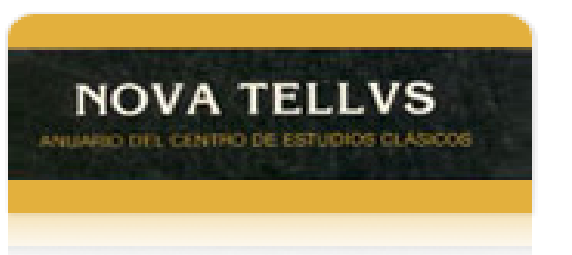

Nova Tellus

ISSN: 0185-3058

novatelu@servidor.unam.mx

Centro de Estudios Clásicos

México

Ramírez Vidal, Gerardo

El êthos y la formación humanística en Isócrates

Nova Tellus, vol. 31, núm. 1, 2013, pp. 103-120

Centro de Estudios Clásicos

Distrito Federal, México

Disponible en: http://www.redalyc.org/articulo.oa?id=59137771004

- Cómo citar el artículo

- Número completo

- Más información del artículo

- Página de la revista en redalyc.org

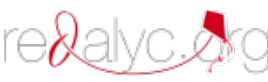

Sistema de Información Científica

Red de Revistas Científicas de América Latina, el Caribe, España y Portugal

Proyecto académico sin fines de lucro, desarrollado bajo la iniciativa de acceso abierto 


\title{
El êthos y la formación humanística en Isócrates
}

Ethos and Humanistic Education in Isocrates

\author{
Gerardo RAMÍREZ VIDAL \\ Universidad Nacional Autónoma de México \\ grvidal18@gmail.com
}

\begin{abstract}
RESUMEN: La retórica fue el modelo fundamental de la educación superior en la antigüedad griega y romana, y siguió siéndolo durante la época medieval y renacentista. Isócrates es reconocido como el maestro de retórica por excelencia en la Grecia antigua y como el fundador de la educación liberal en Occidente. Para él, las "ciencias" tienen una función propedéutica y se encuentran subordinadas a la philosophía de los logoi, expresión con que se designa la formación política. Entre los elementos de su sistema educativo humanístico y retórico destaca el concepto de êthos, que es una precondición del discurso eficaz en la contienda política. Su sentido primario es el de comportamiento esperado del orador que debe ser congruente con la educación recibida, con la tradición familiar y con la orientación política. La función del êthos puede ampliarse a otros campos de la cultura humanística.
\end{abstract}

ABSTRACT: Rhetoric was the main model of higher education in Greek and Roman antiquity, and remained so during the Medieval and Renaissance periods. Isocrates is recognized as the quintessential teacher of rhetoric in ancient Greece and as the founder of liberal education in the West. To him, learning of the "sciences" had only a preparatory function and should be subordinated to the philosophia of logoi (e. g. political training). Among the elements of his humanistic and rhetorical education system, he emphasized the concept of êthos, which he considered as a precondition for effective speech in the political struggle. Its main meaning is the speaker's expected behavior, which should be consistent with his education, his family tradition and his political orientation. The function of êthos can be extended to other fields of humanistic culture.

PaLABRAS ClaVE: êthos, educación, retórica, Isócrates.

KEYWORDS: ethos, education, rhetoric, Isocrates.

RECIBIDO: 22 de octubre de 2013 • ACEPTADO: 27 de noviembre de 2013.

La retórica es el modelo por excelencia de la educación clásica en la antigüedad griega y romana, y fue el legado que perduró otros mil años, durante el Medioevo y el Humanismo, integrado en el famoso Trivium de las artes liberales, que comprendía gramática, dialéctica y retórica. ${ }^{1}$

${ }^{1}$ Marrou 1983, p. 196, se expresa en general del sistema educativo de la siguiente manera: "el sistema educativo que va tomando forma paulatina entre los griegos desde el periodo arcaico hasta el comienzo del dominio romano sería adoptado por los romanos con leves modificaciones e incorporado en consecuencia al legado de Roma; mediante este último influiría profundamente en las instituciones y prácticas educativas de 
Tal parece que ha habido un olvido incomprensible del importante papel que desempeñó esa doctrina en la educación superior en el mundo antiguo de Grecia y Roma. ${ }^{2}$ Los antecedentes de ese tipo de formación ya los encontramos en Homero. De un pasaje de la Ilíada (9.434) se puede conjeturar que la educación de los jóvenes nobles tenía como propósito saber "hablar bien" y llevar a cabo las acciones guerreras. Los áristoi ejercían sus funciones de gobierno en buena medida mediante la palabra y la elocuencia, rasgos muy estimados entre los héroes homéricos, como después lo serán entre los dirigentes políticos. La formación retórica se encuentra muy difundida desde comienzos del siglo $\mathrm{V}$, como se muestra a su plenitud en el Himno a Hermes, donde el niño dios recurre a triquiñuelas de abogado para defenderse de la acusación de robo. ${ }^{3}$ Los destinatarios de ese himno deberían estar familiarizados con ese tipo de procedimientos. También en la filosofía de la época, se empleaba el lenguaje con una función persuasiva y educativa. Por ejemplo, los llamados "discursos pitagóricos" muestran la utilización de recursos como la polytropía en la difusión de la enseñanza. ${ }^{4}$

A los grandes políticos del siglo v, llamados "oradores", se debe en gran medida la gran hazaña de la democracia, y a los maestros de política, conocidos como "sofistas", les cabe el honor de haber establecido las

Europa, influencia reforzada por el retorno a lo antiguo que caracterizó a los sucesivos renacimientos, el carolingio del siglo IX y el humanista de los siglos XV y XVI".

${ }^{2}$ Nietzsche (2000, p. 180) es tajante al respecto: "una de las principales diferencias entre los antiguos y los modernos es el extraordinario desarrollo de la retórica; en nuestra época este arte es objeto de un general desprecio". En las historias generales y tradicionales de la educación se presta atención a la filosofía como proyecto educativo, pero no a la retórica que fue el modelo por excelencia de formación superior. Por si fuera poco, a Sócrates, Platón y Aristóteles se les despoja de cualquier vinculación con la retórica, como si nada tuvieran que ver con ella (cf. Frankena 1965). En descripciones más recientes, aparece ya la retórica como paradigma frente a la filosofía. Un ejemplo singular es Rojas Osorio 2010, quien presenta un interesante resumen de la educación retórica en las páginas 52 y 53, además de abordar a los sofistas (pp. 5-10), a Isócrates (pp. 19-20), para quien la cultura es el bien superior, y a la educación retórica en la Edad Media y durante el Humanismo.

${ }^{3}$ Desde el punto de vista retórico, la obra parece reflejar la situación de la primera mitad del siglo v, lo que permitiría pensar en una datación baja de este himno. Sobre este asunto, cf. Vergados, 203, pp. 138-141, quien defiende una datación media (segunda mitad del siglo VI, p. 147).

${ }^{4}$ Sobre la polytropía en los "discursos pitagóricos" transmitidos por Jámblico, cf. Plebe 1996, p. 18. 
bases de la educación superior en Occidente. También los tres grandes filósofos de los siglos V y IV (Sócrates, Platón y Aristóteles) se ven muy involucrados en la enseñanza de la política y la oratoria. En las Nubes Aristófanes presenta a Sócrates como maestro reconocido del discurso judicial (cf. vv. 478 ss.); en la segunda parte del diálogo Fedro, Platón se muestra como el inventor de una retórica general, con una orientación filosófica; por último, Aristóteles escribió la gran obra de retórica de todos los tiempos, además de los Tópicos y las Refutaciones sofísticas. En general, se prefiere no ahondar en la enseñanza retórica de los tres filósofos mencionados, ${ }^{5}$ pero sí hacer referencia a la polémica entre Isócrates y Platón, donde el último de ambos resulta generalmente victorioso, minimizando así la gran contribución y el éxito obtenido por el primer maestro en el ámbito de la política.

Los ejemplos anteriores son una ligera muestra de lo extendidas que estaban en la Grecia arcaica y clásica las nociones del poder persuasivo y educativo de la palabra. Pero se piensa que la retórica se estableció como el sistema de educación superior en la primera mitad del siglo IV a. C., en la escuela de Isócrates, en Atenas, con tal éxito que después se adoptó y difundió por toda Grecia. Como observa Clark (1963, p. 58):

en Isócrates encontramos el ejemplo más antiguo y más noble de maestro de retórica, el maestro que es experto del arte que enseña, quien se dedica al verdadero provecho de sus discípulos, quien concibe la educación en retórica como la capacitación de la juventud para tomar el lugar que le corresponde en una sociedad humana donde las transacciones se conducen mediante el lenguaje.

En el periodo helenístico, junto a los gimnasios y las bibliotecas, se establecieron también las escuelas de retórica en las ciudades de cierta importancia. Según Henri-Irénée Marrou (1965, p. 239), "la retórica quedó como el objeto específico de la enseñanza superior griega, de la alta cultura”. Algunas de ellas llegaron a ser célebres, como las escuelas de Atenas y Rodas. "Para la gran mayoría de los estudiantes, cursar estudios superiores significaba oír las lecciones del rétor, iniciándose con él en el arte de la elocuencia" (Marrou 1965, p. 239). Ya desde el siglo II a. C., los romanos, guiados por su sentido práctico, adoptaron,

\footnotetext{
${ }^{5}$ Cf., sin embargo, en relación con la retórica en Platón, Yunis 1996.
} 
al principio con recelos, la teoría discursiva de los griegos, adecuándola a los fines propios, a las estructuras políticas y a las prácticas sociales. Los grandes teóricos, como el anónimo autor de la Retórica a Herenio, Cicerón, Quintiliano y muchos otros, dan testimonio de la trascendencia de esa disciplina, pues sus obras fueron el basamento de la educación clásica.

$* * *$

Como hemos dicho, el ateniense Isócrates (436-338) es considerado como el más antiguo y el más destacado representante de esta disciplina en la antigüedad clásica, ${ }^{6}$ y maestro de toda una generación de expertos en el empleo eficaz del lenguaje. Discípulo de Gorgias, Isócrates era diez años mayor que Platón, a quien sobrevivió diez más. En la antigüedad su escuela llegó a ser la más famosa de la Hélade y más reconocida que la Academia y el Liceo, ${ }^{7}$ aunque en nuestro tiempo se acostumbra atribuir de manera errónea ese mérito a estas dos escuelas filosóficas, confirmando así el usual desprecio por la retórica. ${ }^{8}$

${ }^{6}$ Cf. Jaeger, 1962, p. 830: "Dentro del pugilato general del espíritu en torno a la esencia de la verdadera paideia que nos brinda la literatura griega del siglo IV a. C., personifica Isócrates, como el representante más destacado de la retórica, la antítesis clásica de lo que representaban Platón y su escuela". Desde mi punto de vista, la oposición entre Isócrates y Platón no se dio entre retórica y filosofía, sino entre dos tipos de retórica, una caracterizada por su función práctica en el ámbito educativo y político, y la otra por su naturaleza teórica y descriptiva.

${ }^{7}$ Sobre la oposición contra Isócrates por parte de Platón, cf. Pl. Phdr. 279a, y de Aristóteles, cf. Quint. Inst. 3.14, y sobre los críticos de ese maestro, cf. también a Isocr. Antid. (14). Sobre la fama de la escuela en los autores antiguos, cf. los consabidos pasajes de Cic. De or. 2.22, y Quint. Inst. 3.14 y 12.22. Afirma Clark 1963, p. 10: “Así, la escuela de Aristóteles [...] no produjo ningún orador de nota, excepto Demetrio Falereo; la escuela de Isócrates produjo una multitud. ¿Cómo se explica lo anterior? Claramente, porque Isócrates, aunque era inferior en su comprensión de los principios, era ampliamente superior en el ámbito práctico de la enseñanza”.

${ }^{8}$ Sobre este punto es necesario consultar el artículo de Muir 2005, cuyos puntos han sido resumidos por Smith 2008, quien afirma (2005, p. 168): "Despite ample historical evidence of Isocrates' unequalled influence in the history of educational thought and practice $[. .$.$] the impression given by educationist histories of education is that Isocrates$ never existed". Abbagnano y Visalberghi afirman: "Isócrates es el verdadero fundador de la educación de tipo predominantemente literario que caracterizaría la tradición clásica y humanística hasta nuestros días" (1975, p. 70), pero sólo lo abordan en media página, mientras que dedican un capítulo a Platón y otro a Aristóteles. Nietzsche tiene una 
A Isócrates se le ha considerado como el padre de la educación liberal y del humanismo en la tradición occidental. ${ }^{9}$ De esta manera, se ha identificado la retórica con el humanismo, aunque ambas palabras no tienen correspondencia con la terminología empleada por Isócrates, quien estableció lo que hoy podríamos considerar educación superior en la antigüedad griega y romana. Sin embargo, esto último requiere de una explicación.

Se ha acostumbrado a considerar a Isócrates como maestro de retórica, pero él no se definía a sí mismo como tal, y esa palabra nunca aparece en los escritos que de él nos quedan. Fueron los maestros de época posterior quienes lo identificaron de tal forma, y en ese sentido lo seguimos considerando. Pero él se llamaba a sí mismo "filósofo de los logoi" y a su disciplina "filosofía de los logoi". ${ }^{10}$ Sin embargo, se debe aclarar que el maestro no emplea el término philósophos en el sentido hoy tradicional, que es el sentido platónico, sino en el de "experto" 11 en el logos, que

visión diferente y justa, pues Isócrates, "el maestro más grande de la elocuencia” (2000, p. 168), considera el discurso como la causa de toda suprema formación, incluyendo la moral" (2000, p. 191) (cf. también Rojas Osorio 2010, p. 19).

${ }^{9}$ Cf. Jaeger 1962, p. 830: "Isócrates [...] desde el Renacimiento ha dominado incuestionablemente, más que ningún otro maestro de la Antigüedad, la práctica pedagógica del humanismo". A pesar de ello, Jaeger dedica 320 páginas a Platón, mientras que a Isócrates sólo 120. Para Marrou (1965, p. 239): "En el plano histórico, Platón resultó vencido: no logró imponer a la posteridad su ideal pedagógico. Isócrates, en líneas generales, lo aventajó, convirtiéndose en el educador de Grecia primero y, después, de todo el mundo antiguo".

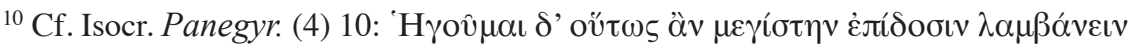

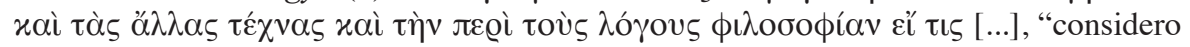
que tendrían el máximo progreso las demás artes y la philosophía de los lógoi, si [...]”, cuya última expresión se ha traducido de maneras diversas como "retórica" (GhirgaRomussi 2001) o "estudio del discurso" (Papillon 2004 y Guzmán Hermida, 2002).

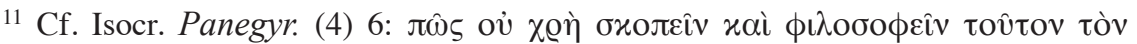

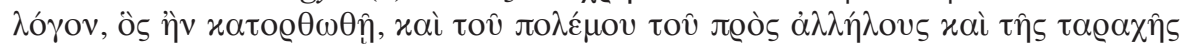

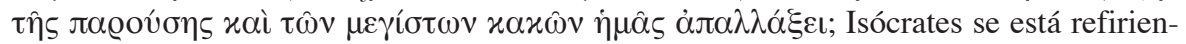
do al conflicto entre las ciudades griegas y el imperio persa que considera es preciso entender, porque el peligro está presente. Chiara Ghirga y Roberta Romussi, traducen la frase de la siguiente manera: "Come posso non applicare tutto il mio acume e la mia cultura a questo discorso che, se ben riuscito, ci liberarà della guerra che ci stiamo facendo e di questo disordine attuale e dai mali peggiori?". En su nota al texto a Isocr.

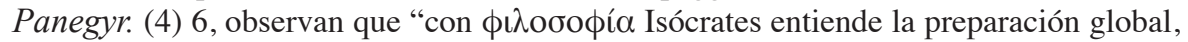
intelectual y moral del rétor educado en su escuela: la $\pi \alpha \iota \delta \varepsilon i ́ \alpha$ fundada en el $\lambda$ ó $\gamma \mathrm{o}$ ”, y reenvía a Antid. (15) 181, 266, 274 ss., Busiris (11) 49 y Areopag. (7) 45. En cambio, Guzmán Hermida traduce “¿Cómo no va a ser necesario el examinar y el estudiar este 
implica también la formación de los jóvenes en el dominio de la eficacia argumentativo-discursiva, puesto que logos significa tanto "argumento" como "discurso". Es en este amplio sentido que podemos considerar a Isócrates como "maestro de retórica", aunque la retórica era sólo una parte de la formación integral del ciudadano que él impartía en su escuela.

Los veintiún discursos y nueve cartas que se conservan de Isócrates estaban orientados a la formación política de los jóvenes. El maestro no publicó ningún manual teórico de retórica, y el que se conserva bajo su nombre, en estado fragmentario, es apócrifo. De tal manera, sus concepciones y elementos retóricos y educativos debemos buscarlos, por una parte, en las alusiones que hace en sus discursos a su actividad pedagógica, en particular aquellos que tratan de modo expreso sobre ello; por otra, en los testimonios antiguos referidos a su escuela, además de los indicios de su sistema que se encuentran en la propia composición discursiva. Su enseñanza abarcaba diversas materias, entre las que se encontraban el derecho, la poesía, la historia, la composición escrita y otras disciplinas humanísticas. Pero debemos siempre tomar en cuenta que el estudio del lenguaje eficaz y de la comunicación de calidad eran una parte de su enseñanza. ${ }^{12}$ En cambio, las artes matemáticas (astronomía, cálculo, y geometría) eran puramente instrumentales y se encontraban subordinadas a lo que el maestro llamaba "philosophía de los logoi" a la cual podemos denominar, "formación discursiva" (pues se refería a las materias que antes se han indicado) y, en sentido amplio, "retórica", 13

discurso que, si tuviera éxito, nos libraría de la guerra entre nosotros, del desorden actual y de los mayores males?".

12 Podemos suponer que la sistematización de las siete artes liberales, elaborada por Marciano Capella en el siglo v de nuestra era, tenía sus orígenes en Isócrates, según el juicio de Muir 2005, p. 13: "Isocrates appears to have originated an educational programme based on seven liberal arts". Tres eran artes del lenguaje y cuatro matemáticas, aunque el número de estas últimas era variable. Todas ellas formaban parte de una disciplina mayor: la filología.

${ }^{13}$ La "philosophía de los logoi" es una doctrina de la formación del hombre, que incluía conocimientos propiamente humanísticos, como la historia, la poesía, la argumentación, el estilo y la composición discursiva. Los conocimientos científicos eran importantes sólo para los jóvenes, antes de dedicarse al estudio en la escuela de Isócrates. En la Academia y el Liceo los estudios científicos podían seguirse también en el nivel superior, como conocimientos filosóficos. En este sentido, Isócrates tenía una orientación humanística, mientras que las escuelas de Platón y Aristóteles, una orientación técnica y científica. 
pero tomando en cuenta que logos significa también razonamiento e implica una formación intelectiva que permita discernir y decidir o aconsejar lo mejor en relación con un determinado problema.

Además de la gravitación de las artes y ciencias en torno a la retórica, ésta se basaba en tres series de capacidades: dotes naturales, técnica y ejercicio, ${ }^{14}$ íntimamente imbricadas entre sí. Dichas capacidades se referían a determinados elementos, como la memoria, la voz, la invención, la comprensión, y una serie de virtudes políticas, cuya posesión o dominio eran necesarios para llegar a ser óptimo orador y pensador. ${ }^{15}$

Sin embargo, debe tomarse en consideración que la intención de Isócrates no era establecer teorías sobre el discurso, sino aconsejar estrategias a sus discípulos con base en discursos escritos que servían como material didáctico en los cuales se fundamentaba la educación.

$$
* * *
$$

Luego de esta sumaria presentación sobre el dúctil "sistema" isocrateo, podemos reflexionar sobre la importancia que tenía dentro de la formación isocratea la presencia del orador: sus actitudes y costumbres, su familia, la edad o la orientación ideológica. Parte muy importante de la educación estaba dirigida a formar éticamente a los discípulos, es decir, a modelar el êthos ( cepto adquiere una importancia capital en ese modelo educativo.

Antes de proseguir, es necesario recordar que el término en cuestión es ambiguo y polisémico en los autores griegos, ${ }^{16}$ incluso dentro de la

${ }^{14}$ Cf. Isocr. Antid. (15) 165, y en particular 189-190 (las cualidades naturales constituyen un elemento indispensable para la educación), 191 (la práctica y el ejercicio permiten superar las deficiencias originales) y 192 (el poder de la educación no es igual ni análogo al de los factores mencionados). En la concepción educativa de Isócrates, la idea de que las dotes naturales tienen mayor importancia frente a la enseñanza resulta paradójica si se trata de un elemento aristocrático, pues Isócrates (quien no poseía esas dotes) no pertenecía a ese sector, sino al de los conocidos como "nuevos ricos". En cambio, si por naturaleza se entiende una capacidad puramente fisiológica, entonces cualquier sujeto es susceptible de poseer dotes y de ser educado.

${ }^{15}$ Cf. Isocr. Antid. (15) 189-190.

${ }^{16}$ Hoy este elemento retórico-educativo es muy estudiado. Entre la extensa cantidad de trabajos al respecto, los estudios reunidos por Ruth Amossy presentan un cuadro general sobre los sentidos fundamentales del $\hat{\eta} \theta$ os que enriquecen la teoría antigua, aunque siempre es necesario volver a las fuentes primarias para entender mejor los 
obra de un mismo autor. En términos generales, la crítica moderna se ha basado sobre todo en Aristóteles, y ha tenido importantes contribuciones al respecto que enriquecen la teoría antigua, sin embargo, en este caso nos apartamos del concepto tradicional de carácter que se da a esa palabra. Preferimos considerar el $\hat{\eta} \theta$ os como el comportamiento o la actitud esperada de una persona o grupo de personas, que está en sintonía con o es el resultado de un conjunto de costumbres (ethê, (hexeis, $\check{\varepsilon} \xi \varepsilon ı \varsigma)$ y condiciones físicas (edad, sexo, etc.) o de la fortuna,

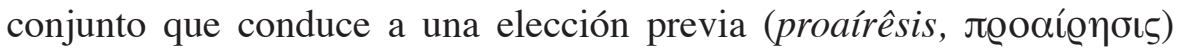
frente a una disyuntiva. No existe una única traducción que pueda dar cuenta de su sentido en general: el êthos del juez en la Grecia clásica es ser justo; el del político, democrático, equitativo o igualitario; el del filósofo, honesto frente a la verdad; el del padre, responsable... ${ }^{17}$ Por ello, lo que Isócrates pretendía en su escuela no era enseñar retórica en sentido teórico, sino hacer de sus discípulos hombres honestos y justos que pudieran ofrecer los mejores consejos. Esta noción corresponde en latín a bonus en la expresión vir bonus dicendi peritus, ${ }^{18}$ de modo que esa palabra debe entenderse no como "bueno" en sentido abstracto, absoluto o moral, sino más bien como agathós, epieikês o kalós, en referencia al hombre que se comporta bien con su régimen político, con los ciudadanos, con sus amigos, más su comportamiento no es necesariamente igual con todos los hombres, en todas partes y siempre. De ahí proviene el sentido de "ética" como una disciplina que aborda el comportamiento (êthos) del ciudadano acomodado a los intereses y a las expectativas de su comunidad. Por otro lado, el êthos no sólo lo posee el emisor, sino que se encuentra en diverso grado en las diversas personas: primera, segunda y tercera, e incluso en las comunidades retóricas.

Así el orador - conocedor de todo ello- debe utilizar los diversos êthê o comportamientos esperados para persuadir a los jueces, los ciudadanos o los simples espectadores. Ahora, el êthos puede ser preexistente o bien inducido. El primero corresponde a la doxa o auctoritas que una

límites y la función de ese concepto, asunto que ha abordado con gran detalle y tacto Woerther 2007.

${ }^{17}$ Cf. Vianello 2004, pp. 43-44, donde se puede observar el empleo de diferentes expresiones que sustituyen el término êthos: khrestós, dikaios y, sobre todo, agathós. Véase también el estudio del êthos en un caso específico en Vianello 2007.

${ }^{18}$ Expresión que Quintiliano atribuye a Catón el Censor (Inst. 12.1.1). 
persona posee de por sí; es un medio no técnico: el hablante enuncia los datos de manera más o menos intencional acerca de sí mismo, o un tercero da referencias del hablante; el êthos inducido es el técnico, creado por el orador mediante la lengua, de modo que el hablante dé la apariencia de ser de una determinada manera. ${ }^{19}$ Para ello se emplean diversas estrategias, como el uso de sentencias, el ordenamiento de las partes, la elaboración de un estilo ajustado al destinatario, la actuación que dé la impresión de ser una persona justa, equitativa, honesta. ${ }^{20}$ También los destinatarios, los grupos sociales o los regímenes políticos presentan un determinado êthos al que el orador se debe amoldar si no lo comparte, para obtener su confianza y, en última instancia, modificarlo o reforzarlo.

En Isócrates no encontramos una teoría definida al respecto, aunque probablemente no desconocía los usos instrumentales del $\hat{\eta} \theta 0 \varsigma^{21}$ para atraerse la adhesión del auditorio, ${ }^{22}$ e incluso tal vez Aristóteles partió de él para innovar su célebre teoría del êthos del orador mediante el lenguaje. ${ }^{23}$ En Isócrates encontramos una noción de un $\hat{\eta} \theta$ os que podríamos llamar primario, a partir del cual Aristóteles inventó el nuevo concepto

${ }^{19}$ Aristóteles se refería, en especial, al ع̌ $\theta$ o inducido, concepción que ha parecido muy reducida a los estudiosos modernos que han observado las otras dos formas de construir la imagen de sí mismo.

${ }^{20}$ Podría pensarse que existe también un $\eta^{0} 0$ os en la lengua o pragma-semántico: la información se vehicula en la propia lengua de manera involuntaria, no intencional, pero su estudio pertenece a la lingüística, no a la retórica.

${ }^{21}$ Cf. Aquino López 2004a, donde se muestra que el êthos del orador X tiene tres elementos fundamentales: la amistad, las buenas acciones realizadas con el fallecido y, finalmente, la posesión de un testamento. Todo ello, en efecto, otorga confianza en la honestidad del orador.

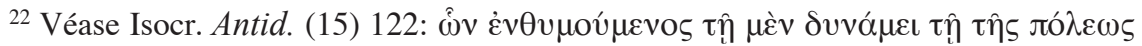

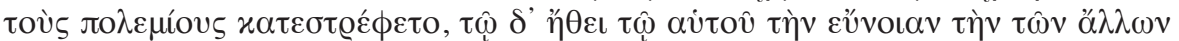

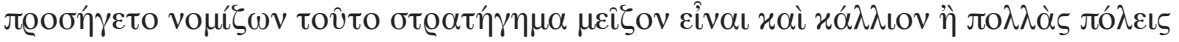

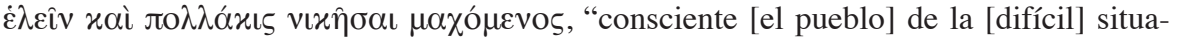
ción, con el poderío [bélico] de la ciudad sometía a las fuerzas enemigas y con sus propios modales se atraía la simpatía de los demás, considerando que esta estratagema era mejor y más hermosa que tomar y vencer con frecuencia a muchas ciudades con

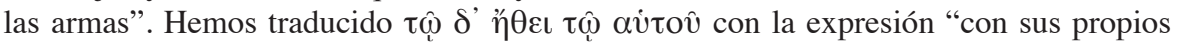
modales", entendiendo que se refiere a la actitud que se esperaba de Atenas frente a ciudades no enemigas, ya fueran neutrales o más débiles militarmente.

${ }^{23}$ Este es el punto tratado de manera estupenda por Woerther 2007, pp. 205-254, al que agrega el "tratado de los caracteres" (2007, pp. 255-297), expuesto por el filósofo en el segundo libro de su Retórica (caps. 12-17). 
del "êthos del orador". La revisión de algunos pasajes nos permitirá extraer algunas connotaciones interesantes de ese término mediante su

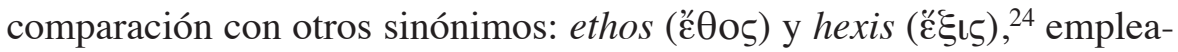
dos con un sentido peculiar muy significativo, pues permite entender de manera precisa el sentido de la ética como parte de la filosofía.

A los estudiosos les ha interesado distinguir sobre todo entre êthos

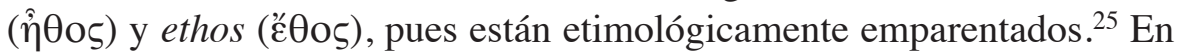
Isócrates, el uso de ambas palabras es claro. El ع̋日os, que aparece cinco veces en este orador, se refiere sobre todo a una costumbre establecida, como aquella que prohíbe dejar insepultos a los muertos, ${ }^{26}$ o la de interrumpir las hostilidades durante las grandes celebraciones nacionales (Panegyr. (4) 43. Se trata, pues, de un nomos, de una ley consuetudinaria. ${ }^{27}$ En el Acerca de la paz (8) 91, se habla del ع̋ $\theta$ os del tirano, que

${ }^{24}$ Se acostumbra traducir $\grave{\jmath} \theta$ os por "carácter", pero este término tiene un sentido

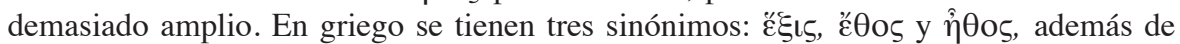

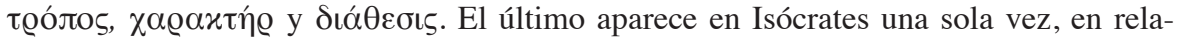
ción con la "distribución" de los productos del campo (Busiris (11) 14), al igual que $\chi \propto \varrho \alpha \chi \tau \eta ́ \emptyset$, que indica la marca o marcas distintivas de una persona, en el siguiente

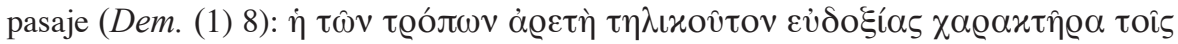

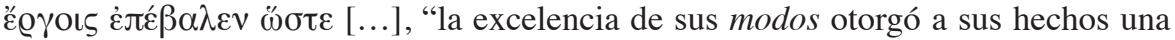
marca tal de gloria que [...]". Aunque este discurso no es auténtico, muestra la dife-

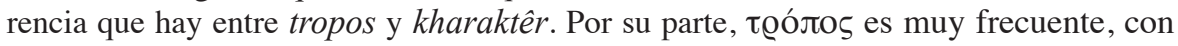
el sentido común de "modo de ser", "de este modo", etc., como vimos en el pasaje

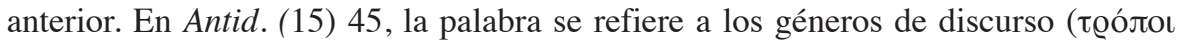

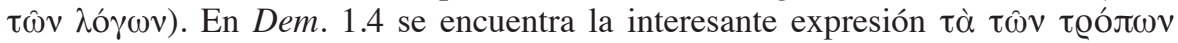
$\eta \emptyset \eta$ : "las actitudes de sus modos". Se trata de un término laxo, muy cercano semánticamente a $\hat{\eta} \theta$ os. En cuanto a $\check{\varepsilon} \xi ı \varsigma$, de manera general, podemos decir que es el "hábito" o "disposición" ("aquello que se tiene" como propio, del verbo ع̌ $\chi \omega)$ ) el čӨos es la costumbre o conducta (de عُ $\theta \omega$, "acostumbro”). En Isócrates existe un empleo particular, como veremos.

25 Ambos provienen de la misma raíz que con alternancia vocálica se expresa *swedh-, *swêd-, *swodh- (cf. lat. suesco). Según parece, en su origen la raíz tenía el sentido de "costumbre", pero en plural, en Homero y Hesíodo, significa "morada" o "lugar" donde se recogen hombres o animales, como en Il. 6.511 y Od. 14.411; Hes. $O p .167$ y 525 (el verso 222 es problemático). En Hes. Op. 61 se encuentra, en singular, ya con el significado de "hábito", "disposición".

${ }^{26}$ Isocr. Panegyr. (4) 55, Panath. (12) 169.

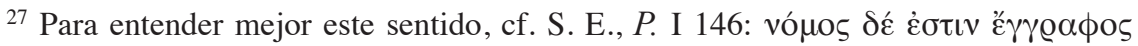

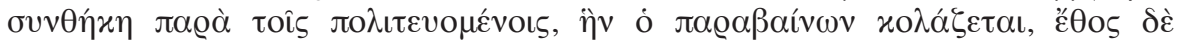

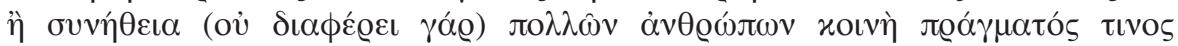

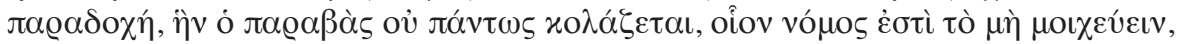

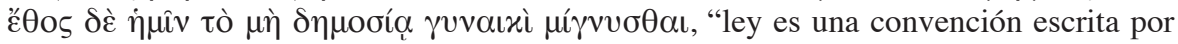


puede entenderse como un nomos o ley no escrita: "se ha establecido como ley (ç0os) para los tiranos el procurarse sus placeres con los esfuerzos y los sufrimientos" del pueblo. ${ }^{28}$

En cambio, puede observarse que $\hat{\eta} \theta$ os se refiere a la conducta o disposición anímica que, por una parte, es apropiada a y congruente con una persona, grupo o comunidad y, por otra, que esta conducta ha sido construida o enseñada, es decir, no se trata de una costumbre heredada y persistente, sino de una actitud que se ha formado previamente ${ }^{29}$ en una persona y que, en consecuencia, puede mantenerse en ella o abandonarla. A ello se debe que en los textos aparezca con frecuencia la expresión "permanecer en esa actitud", pues, en efecto, podría no proceder de acuerdo con lo esperado. ${ }^{30}$ No se trata, en suma, de una concepción estática acerca de alguien, sino de una conducta mudable, aunque podemos suponer que el $\hat{\eta} \theta$ os se basa en el है $\theta$ os; que es lo mismo que decir que la conducta se basa en la costumbre. ${ }^{31}$

La semejanza es mayor entre $\hat{\eta} \theta$ o y $\check{\varepsilon} \xi ı$. En términos generales podremos decir que $\check{\varepsilon} \xi ı$, sustantivo verbal de $\varepsilon \chi \chi \omega$ ("tener", "poseer"), se

los ciudadanos cuya violación es penada, y ع̋ 0 o s o costumbre (pues no difieren) es una costumbre hereditaria común de muchos hombres sobre algún asunto cuya violación no es penada en absoluto. Por ejemplo, una ley es no cometer adulterio, y un ع̋ $\theta$ o es el no tener relaciones con una prostituta".

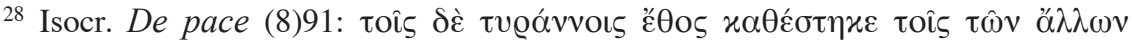

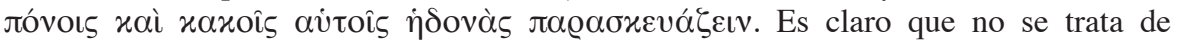
una ley establecida, de una ley positiva, sino de una costumbre muy arraigada. En cambio, es problemático el pasaje del Antídosis (15) 206, donde el autor se refiere al legado educativo común que los discípulos conservan de sus grandes maestros y que los distingue, y prosigue diciendo que cuando no tienen un ع̌Өo somún ni una activi-

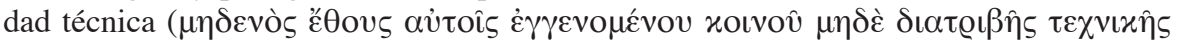

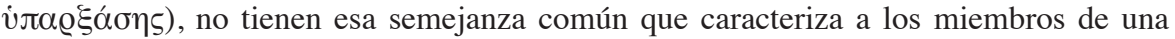
escuela. Aquí č $\theta$ os podría referirse a una norma consuetudinaria que los condiscípulos heredan del maestro.

${ }^{29}$ Son elementos que el orador tiene a su disposición y no debe inventar, sino acentuar.

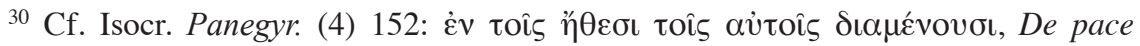

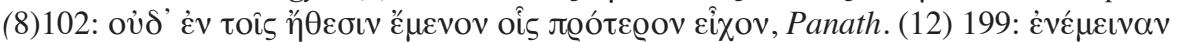

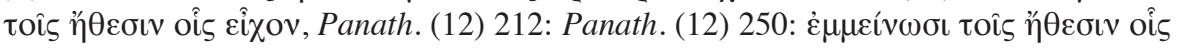

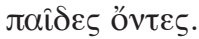

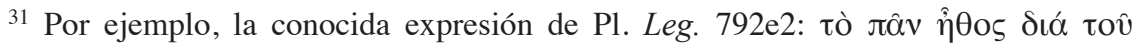
ع̋'0ous. Cf. Arist. E. N. 1103a15-20 (Woerther 2007, p. 154) y Aquilius (Rashed 2012):

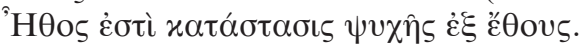


refiere al conjunto de hábitos espirituales ${ }^{32}$ que posee una persona, en analogía y oposición a las disposiciones físicas, como aparece claramente delineado en el discurso Antídosis (15) 185, escrito hacia el 354-353 a. C. En el Panatenaico (12) 30-32, que es la última de sus obras (342-339 a. C.), Isócrates considera como hombres prudentes, perfectos y provistos de todas las virtudes a aquellos que tienen un hábito espiritual ajustado a un conjunto de capacidades intelectivas y comportamientos adquiridos mediante la educación ( $\pi \varepsilon \pi \alpha \iota \delta \varepsilon v \mu \varepsilon ́ v o v \varsigma)$ que consisten en: ${ }^{33} a$ ) saber afrontar los problemas cotidianos, tener opiniones apropiadas sobre los momentos oportunos y ser capaces de conjeturar lo que es útil; $b$ ) ser personas corteses y condescendientes; $c$ ) tener la capacidad de dominar sus pasiones y las desventuras, y $d$ ) sobre todo, ser personas modestas, que no se vanaglorien de sus éxitos. ${ }^{34}$

Como podrá observarse, en términos generales, el sentido de $\hat{\eta} \theta$ o $\varsigma$ es semejante al de $\check{\varepsilon} \xi ı$, pues se refiere también al comportamiento adquirido por una persona durante su juventud, heredado de sus antepasados, o uno mismo lo manifiesta. Un par de ejemplos ilustrará lo anterior. Un caso se encuentra en el discurso judicial de principios del siglo IV (397-396), intitulado Acerca del tiro de caballos (16). Ahí (§ 28), el joven Alcibiades, hijo del gran dirigente ateniense homónimo, encomia a su padre señalando que éste había tenido por tutor, educador y maestro a Pericles, al que califica como el más prudente, el más justo y el más capaz de todos los ciudadanos, cualidades (o hexeis, podría agregarse) reconocidas por todos y que en su conjunto constituyen el $\hat{\eta} \theta$ os del maestro que debieron quedar impresas en el discípulo. Otro caso se encuentra en el Areopagítico (7), obra escrita hacia el 357 a. C. Ahí Isócrates se refiere a la concepción que los jueces del tribunal del Areópago tenían de las leyes: éstas no son garantía de buen gobierno, para lograrlo es suficiente el $\hat{\eta} \theta$ os o la actitud o comportamiento que los ciudadanos han adquirido durante su crecimiento ( $\$ 40)$, pues quien gobierna bien no necesita llenar los pórticos de leyes escritas; las ciudades son bien gobernadas gracias no a decretos sino a los êthê, a los comportamientos que los ciudadanos esperan de sus gobernantes ( $§ 41)$.

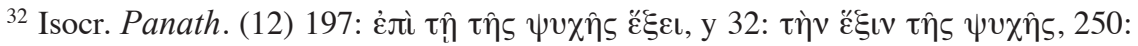

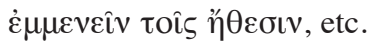

${ }^{33}$ Estas virtudes espirituales se adquieren mediante el estudio y pueden heredarse de padres a hijos (Pax (8) 90) o perderse (Panath. (12) 58).

${ }^{34}$ Isocr., Panath. (12) 30-32. 
Por tanto, las dos series de ejemplos, tanto de $\hat{\eta} \theta$ o como $\check{\varepsilon} \xi ı \varsigma$, muestran que en Isócrates ambos términos tienen un sentido semejante. Pero hay particularidades que los distinguen.

Por una parte, tanto $\hat{\eta} \theta$ o como $\check{\varepsilon} \xi ı \varsigma$ se refieren a virtudes políticas, como la fortaleza y la prudencia,${ }^{35}$ o la justicia y la capacidad, antes vistas. Sin embargo, al $\hat{\eta} \theta$ os lo conforman un conjunto de rasgos, entre los que se encuentran las hexeis. Aunque a veces hay confusión, el primer término engloba al segundo, junto con otras cualidades como la edad o la fortuna, por ejemplo.

En segundo lugar, mientras la $\check{\varepsilon} \xi ı \varsigma$ designa un conjunto de cualidades habituales, el $\hat{\eta} \theta$ os se refiere, de manera deóntica, al modo de actuar que se espera del orador, cuya actitud debe ser consecuente con el régimen o grupo político, con los fundadores, con su condición o rango, con la familia o con la enseñanza que ha recibido desde joven. Así, el $\hat{\eta} \theta$ o $\varsigma$ constituye un elemento imprescindible en la lucha política, pues se espera que los políticos tengan un comportamiento adecuado ya sea con la democracia, la aristocracia o la tiranía, etcétera. En el caso del hijo de Alcibíades, el comportamiento que se espera de él es que sea prudente, justo y capaz, pues fue educado con esos principios. Pericles posee esas cualidades en cuanto maestro; de no ser así, Isócrates podría haberlas designado como hexeis. También en el caso de los jueces del Areópago se espera que actúen de acuerdo con lo que son: hombres experimentados, serios y prudentes. El $\hat{\eta} \theta$ os es, pues, un valor o cualidad política que se espera de alguien.

Por último, se ha observado que $\check{\varepsilon} \xi ı \varsigma$ se traduce con la palabra latina habitus. Ambos términos pueden referirse al conjunto de valores interiorizados y fijos. En cambio, ทें os tiene un principio activo, práctico, político, referido a comportamientos o actitudes que encontraremos desarrolladas ampliamente en el De la invención de Cicerón, ${ }^{36}$ y que, en otros

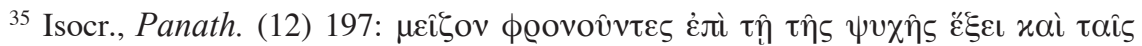

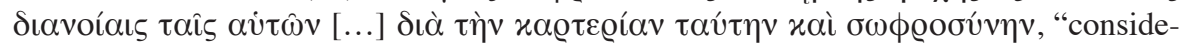
rándose mejores por su hábito espiritual y por sus propios pensamientos [y eran objeto de la admiración de todos] gracias a esta fortaleza y prudencia”.

${ }^{36}$ Cic. De inv. 2.159-176, donde se dividen en dos las cosas deseables: lo honesto y lo útil. Lo honesto, a su vez, se divide en prudencia, justicia, fortaleza y templanza. Cicerón distingue entre virtudes y deberes. Entre las primeras incluye la sabiduría; entre las segundas, la prudentia, que es rerum expetandarum fugiendarum scientia, o "conocimiento de las cosas deseables y de las cosas evitables" (De offic. 1.43.153). Es digno de destacarse que Cicerón llama a esas actitudes "cosas deseables" . 
contextos, serán denominados como "virtudes cardinales". Podríamos decir que una actitud o comportamiento "ético" es aquel que se adecua a la idea que se tiene del grupo, familia, etcétera.

Un ejemplo podrá auxiliarnos a entender el sentido activo de $\hat{\eta} \theta 0 \varsigma$. El pasaje clave se encuentra en el discurso titulado Filipo (5), escrito hacia el 346, poco después de la muerte de Platón. En ese discurso Isócrates menciona las diferencias que pueden observarse entre un discurso oral y otro escrito, siendo este último el que se encuentra en desventaja frente al primero. El autor dice $(\S 26)$ :

En efecto, cuando un discurso está falto de la fama del orador, de la [buena] voz y de los efectos que se dan en la actividad oratoria, y aun más de [la percepción de] los momentos oportunos y del esfuerzo que se da en la práctica y no hay ningún apoyo para el debate y la persuasión, sino que está vacío y desnudo de todos los elementos antes dichos, y [cuando] se lee sin convicción y no se imprime una actitud [adecuada], como si fuera un simple inventario, lógicamente, creo, parecerá a los oyentes algo trivial. ${ }^{37}$

En el pasaje anterior Isócrates explica en qué se manifiesta la inferioridad de los discursos escritos frente a los orales que eran pronunciados ante los ciudadanos. Ello se debe a que los discursos escritos están desprovistos de diversos elementos creadores de persuasión. Es claro que no se refiere al orden ni al contenido ni al estilo, elementos comunes en ambos discursos, sino a componentes propios de la actuación, de la adecuación y del brío y personalidad del orador. Entre las pérdidas en los textos leídos se encuentra el $\hat{\eta} \theta$ os, que es un elemento presente en la palabra oral cuando se busca persuadir a los destinatarios. En este caso, el $\hat{\eta} \theta$ os se refiere al modo en que el orador se presenta físicamente, mediante la voz, los gestos y los ademanes, que le permiten expresar su conformidad con los oyentes. Esta conformidad se puede mostrar de muy diversas maneras: en las sentencias, en el orden del discurso elegi-

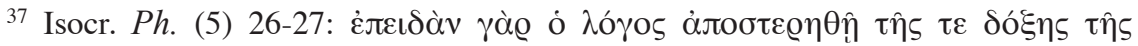

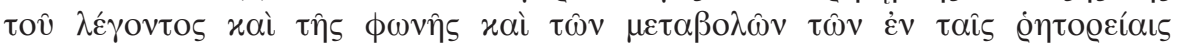

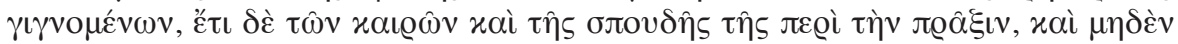

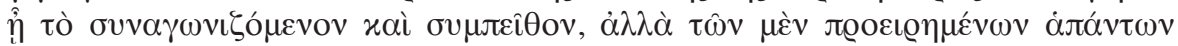

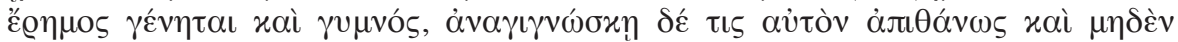
ทें

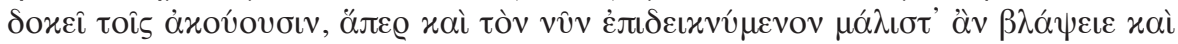

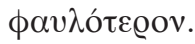


do, en el estilo adecuado y, como se señala en este pasaje, en la puesta en escena, que implica la presencia del orador, con su prestigio y sus dotes escenográficas. Todos estos elementos muestran la adecuación del emisor al receptor, la sintonía que debe haber entre ambos para que pueda haber pistis, que es confianza o crédito, lo cual es precondición del éxito en la lucha política. Los ciudadanos o un grupo social votan a favor del orador no tanto por su programa político, sino por la adecuación de su $\hat{\eta} \theta$ os. No apegarse a este principio puede acarrear consecuencias funestas: los atenienses perdieron su imperio, precisamente por no haber cumplido con las precondiciones éticas para conservarlo. ${ }^{38}$

En cuanto principio activo, el $\hat{\eta} \theta$ os se emplea en el sentido de comportamiento o actitud propia, sobre todo, del hablante y, en segundo lugar, del público o de terceras personas. ${ }^{39} \mathrm{El}$ maestro se refiere a que ese elemento de la persuasión falta en la lectura en voz alta ( $\alpha v \alpha \gamma(\gamma v \omega ́ \sigma x \eta ฺ)$, es decir, en quien pronuncia un discurso político. Además, el êthos es un fenómeno que no se limita al orador político, sino que puede extenderse a cualquier hablante.

En todos los casos, el $\hat{\eta} \theta 0 \varsigma$ es precondición de la eficacia discursiva. Un orador debe adecuarse a las expectativas de los destinatarios. En el Panatenaico (12) 139, Isócrates menciona que los reyes de Atenas habían educado a los ciudadanos en la virtud, la justicia y la prudencia, ${ }^{40} \mathrm{y}$ los ciudadanos, educados en la democracia, elegían como sus dirigentes

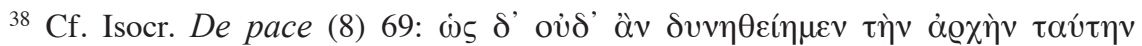

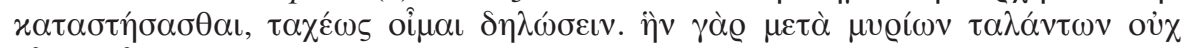

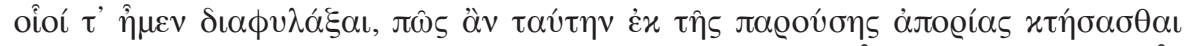

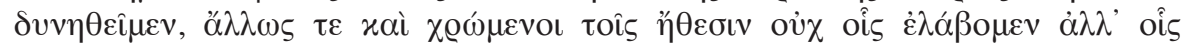

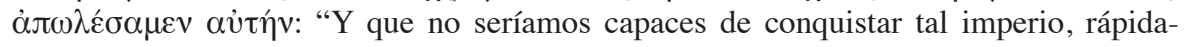
mente - creo - os lo mostraré; si no fuimos capaces de conservarlo con diez mil talentos, ¿cómo entonces podríamos ser capaces de obtenerlo si nos encontramos hoy sin recursos, y si, sobre todo, tenemos los comportamientos no con los que lo obtuvimos, sino con los que lo perdimos?".

${ }^{39}$ En Isócrates existe una teoría aplicable de manera general, pero aquí nos referimos sólo al orador. Un ejemplo de la importancia que se le da al $\hat{\eta} \theta$ o $\varsigma$ en la actividad militar lo encontramos en el $A$ Nicocles (2) 31, donde se observa que para que un pueblo pueda obtener una victoria ante sus enemigos es necesario tener una actitud mental adecuada para ello. Observemos también que Isócrates se refiere no al $\hat{\eta} \theta 0 \varsigma$ individual, sino al

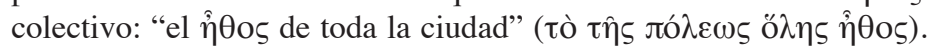

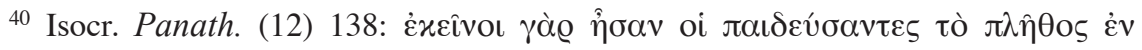

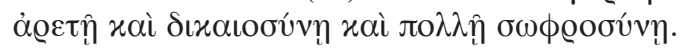


a quienes eran partidarios de la democracia y tenían la misma actitud

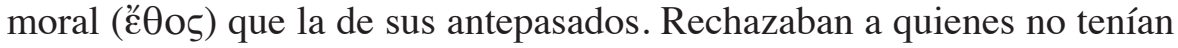
esa disposición favorable: personas malas y moralmente reprobables, que habían dilapidado la herencia paterna o hablaban para elogiar o se apropiaban de los fondos públicos, aunque aparentaran todo lo contrario (140-142). En otras palabras, los atenienses no se fiaban de las palabras; además tomaban en consideración la conducta y la forma de vida de los políticos, quienes debían hacer gala de su predisposición al régimen político mediante un discurso ético, adaptado a la democracia o a la oligarquía. ${ }^{41}$ Se trata de una idealización acerca de la forma en que los atenienses escogían a sus dirigentes y tomaban sus decisiones, pero de cualquier modo la actividad práctica en la tribuna requería de ese ideal de comportamiento.

Esta visión propia en el ámbito político, puede ampliarse a otros campos de acción, como el de la medicina, la arquitectura y la educación, en particular la superior. En la Grecia antigua, el propio Isócrates se presentaba como el ejemplo más idóneo de lo que debe ser un maestro, dedicado a formar políticos con un comportamiento ético. Pero él no intentaba inducir el êthos del filósofo (en el sentido actual, que es el platónico-aristotélico), sino el del ciudadano preocupado por el futuro de su ciudad. Para Isócrates (a diferencia de Platón y Aristóteles), dado que no está en la naturaleza del hombre alcanzar conocimientos verdaderos, las ciencias (y la filosofía) deben tener sólo un papel propedéutico e instrumental; en cambio, como el ser humano sólo puede aspirar a las opiniones - según el orador-, el ciudadano debe esforzarse por alcanzar los mejores juicios y tomar las decisiones justas. Y ello se logra sólo con el estudio y la práctica del derecho, la historia, la literatura, la política y la composición discursiva o retória. Éste es el verdadero humanismo.

${ }^{41} \mathrm{Si}$ vive en un régimen oligárquico, el orador se debe adaptar al êthos de ese régimen, para poder persuadir, pero si vive en uno democrático debe hacer lo mismo. En el casó del régimen democrático en Atenas, no está clara la posición de Isócrates frente a él, pues él también se adapta a los vaivenes de la política, además del desarrollo que tuvo su propia posición al respecto a lo largo de su vida. 


\section{BIBLIOGRAFÍA}

\section{Fuentes}

Isocrate, Discours, vol. I, texte établi et traduit par G. Mathieu et É. Brémond, Paris, Les Belles Lettres, $1972^{4}$.

Isócrates, Discursos, traducción y notas de J. M. Guzmán Hermida, Madrid, Biblioteca Clásica Gredos, 2002.

IsOCRATES II, translated by T. L Papilon, Austin, University of Texas Press, 2004.

Isocrate, Orazioni: Panegirico, Areopagitico, Sulla pace, Filippo, Panatenaico, introduzione, traduzione e note di Ch. Ghirga e Roberta Romussi, testo greco a fronte, Milano, Rizzoli, 2001.

Aquilius, "Les définitions d'Aquilius", M. Rashed (ed.), Bulletin of the Institute of Classical Studies, 55(1), 2012, pp. 131-172.

\section{Estudios}

Abbagnano, N. y A. Visalberghi, Historia de la pedagogía, México, FCE, 1975.

Amossy, R. (ed.), Images de soi dans le discours. La construction de l'ethos, Lausana, Delachaux et Niestlé, 1999.

AQuino López, S., "El ethos retórico en el Eginético de Isócrates”, Jornadas filológicas 2002. Memoria, México, UNAM, 2004a, pp. 393-403.

_, "Isócrates logógrafo y educador", en Vianello de Córdova, P. et al., Oratoria griega y oradores áticos del primer periodo (de fines del siglo $\mathrm{V}$ a inicios del siglo IV a. C.), México, UnAm, 2004b, pp. 105-120.

BenOIT, W. L., "Isocrates on Rhetorical Education", Communication Education, 1984, pp. 109-119.

Clark, D. M., Rhetoric in Greco-Roman Education, New York / London, Columbia University Press, 1963.

Frankena, W. K., Tres filosofías de la educación en la historia, México, UTEHA, 1968.

JAeger, W. Paideia. Los ideales de la educación griega, México, FCE, 1962.

Kennedy, G. A. "Isocrates", en George A. Kennedy (ed.). Cambridge History of Literary Criticism, vol. 1, Cambridge, Cambridge University Press, 1989, pp. 185188.

Marrou, H.-I., Historia de la educación en la antigüedad, Buenos Aires, Eudeba, 1965.

_, “7. Educación y retórica”, en M. I. Finley (ed.), El legado de Grecia. Una nueva valoración, Barcelona, Grijalbo, 1983, pp. 196-212.

Miller, A. B., "Aristotle on Habit and Character: Implications for the Rhetoric." Communication Monographs 41, 1974, pp. 309-316.

MuIR, J. R., "Is our history of educational philosophy mostly wrong? The case of Isocrates", Theory and Research in Education, 3(2), 2005, pp. 165-195. 
Murray, A. T., "Plot and Character in Greek Tragedy", Transactions and Proceedings of the American Philological Association, 47, 1916, pp. 51-64.

Nietzsche, F., Escritos sobre retórica, edición y traducción de L. E. de Santiago Guervós, Madrid, Trotta, 2000.

PleBe, A., Breve storia della retorica antica, Roma-Bari, Laterza, 1996.

Rojas Osorio, C., Filosofía de la educación. De los griegos a la tardomodernidad, Medellín, Editorial Universidad de Antioquía, 2000.

Reynolds, N., "Ethos as Location: New Sites for Discursive Authority", Rhetoric Review, 11.2, 1993, pp. 325-338.

Vergados, A., The "Homeric Hymn to Hermes". Introduction, Text and Commentary, Berlin / Boston, De Gruyter, 2013.

Vianello de Córdova, P., "Oratoria y ethos", en Vianello de Córdova et al., Oratoria griega y oradores áticos del primer periodo (de fines del siglo $\mathrm{V}$ a inicios del siglo IV a. C.), México, UnAM, 2004, pp. 35-45.

_, "El $\hat{\eta} \theta 0 \varsigma$ del orador: Aristóteles, Dionisio de Halicarnaso y Lisias", Noua Tellus, 25(1), 2007, pp. 21-39.

Yunis, H., Taming democracy. Models of Political Rhetoric in Classical Athens, Ithaca / London, Cornell University Press, 1996.

Woerther, F. L'èthos Aristotelicien, genèse d'une notion rhétorique, Paris, Librairie Philosophique J. Vrin, 2007. 